\title{
PENGARUH APLIKASI PACLOBUTRAZOL DENGAN KONSENTRASI DAN FREKUENSI BERBEDA TERHADAP PERTUMBUHAN TAJUK TANAMAN UBI KAYU (Manihot esculenta Crantz.)
}

\author{
Ade Fitri Anggraeni, Muhammad Kamal \& Sunyoto \\ Jurusan Agroteknologi Fakultas Pertanian Universitas Lampung \\ Jl. Prof. Dr. Soemantri Brodjonegoro No. 1 Bandar Lampung 35141 \\ Email: adefitri111@gmail.com
}

\begin{abstract}
ABSTRAK
Aplikasi paclobutrazol merupakan salah satu cara untuk mengurangi tingkat kompetisi antar tanaman terutama tanaman yang ditanam dengan sistem tumpangsari. Pada penelitian ini digunakan tanaman ubi kayu, tanaman ubi kayu dapat dibudidayakan secara tumpangsari namun memiliki tajuk yang tinggi dan lebar. Tujuan dari penelitian ini adalah untuk mengetahui pengaruh aplikasi paclobutrazol terhadap pertumbuhan tajuk tanaman ubikayu, dan untuk mengetahui konsentrasi dan frekuensi aplikasi paclobutrazol yang dapat menghambat sementara pertumbuhan tajuk tanaman ubikayu. Percobaan disusun dalam Rancangan Acak Kelompok (RAK) dengan tiga ulangan. Perlakuannya adalah 0 ppm (kontrol), 200 ppm dengan 2 kali aplikasi, 200 ppm dengan 3 kali aplikasi, 400 ppm dengan 2 kali aplikasi, 400 ppm dengan 3 kali aplikasi, 600 ppm dengan 2 kali aplikasi dan 600 ppm dengan 3 kali aplikasi. Setiap perlakuan terdiri dari 3 tanaman contoh. Hasil penelitian menunjukkan bahwa aplikasi paclobutrazol konsentrasi 200 ppm dengan 2 kali aplikasi menghambat sementara tajuk tanaman ubikayu dengan menghambat pertumbuhan tinggi tanaman pada $5 \mathrm{mst}$ sampai $11 \mathrm{mst}$, tetapi tidak menurunkan bobot ubi secara nyata.
\end{abstract}

Kata kunci : frekuensi, konsentrasi, paclobutrazol, tajuk, ubikayu

\section{PENDAHULUAN}

Ubi kayu (Manihot esculenta Crantz.) merupakan komoditas yang menjadi salah satu bahan pangan pokok bagi masyarakat Indonesia. Ubi kayu menempati urutan ketiga sebagai sumber karbohidrat penting setelah padi dan jagung. Ubi kayu dimanfaatkan untuk pangan baik secara langsung (pengolahan tradisional) maupun melalui pengolahan (industri), serta untuk pakan dan industri non-pangan. Ubi kayu digunakan sebagai bahan baku industri tapioka, industri kertas, plywood, alkohol atau etanol (Hafsah, 2003). Kamal (2011) mengungkapkan bahwa pertumbuhan dan perkembangan tajuk ubi kayu yang relatif lambat pada fase awal pertumbuhanya sehingga ruang tumbuh antara tanaman ubikayu dapat ditanami dengan tanaman palawija.

Permasalahan utama pada sistem tumpang sari ini adalah persaingan untuk memperoleh unsur hara, air dan cahaya matahari antar tanaman yang dibudidayakan. Pada sistem tumpangsari dengan ubi kayu salah satu persaingan yang sangat berpengaruh adalah penyerapan cahaya matahari akibat naungan yang ditimbulkan oleh tajuk tanaman ubi kayu. Hal ini akan mempengaruhi hasil sintesa (glukosa), sehingga dibutuhkan peningkatan berbagai teknologi budidaya terhadap sistem tumpangsari ubi kayu dan tanaman palawija. Untuk menghindari terjadinya persaingan terutama terhadap penerimaan cahaya matahari akibat tajuk tanaman ubi kayu. Salah satu caranya yaitu dengan pemberian paclobutrazol sehingga pertumbuhan tanaman ubi kayu bisa terkendali.

Paclobutrazol merupakan bahan penghambat pertumbuhan yang bekerja pada bagian meristem dengan cara menghambat biosintesa giberelin (GA), sehingga terjadi penghambatan terhadap perpanjangan sel (Berova, dkk., 2002). Syahid (2007) yang menyatakan bahwa jumlah daun tanaman temulawak tidak berpengaruh nyata pada perlakuan paclobutrazol $(1,0$ $5,0 \mathrm{mg} / \mathrm{l}$ ). Syam'un, dkk. (2008) menyatakan bahwa senyawa penghambat pertumbuhan seperti paclobutrazol bekerja untuk menghambat pembelahan sel meristem apikal pada tunas atau pucuk, tetapi sedikit pengaruhnya pada produksi jumlah daun.

Dalziel dan Lawrence dalam Davis, dkk. (1988) melaporkan bahwa kandungan klorofil pada kloroplast meningkat pada tanaman Beta vulgaris yang diberi paclobutrazol. Lebih lanjut Ani (2004) menyatakan bahwa pemberian paclobutrazol meningkatkan jumlah 
klorofil pada stek kentang varietas Granola. Penelitian ini bertujuan untuk mengetahui pengaruh aplikasi paclobutrazol terhadap pertumbuhan tajuk tanaman ubikayu dan untuk mengetahui konsentrasi paclobutrazol dan frekuensi aplikasi yang dapat menghambat sementara pertumbuhan tajuk tanaman ubikayu

\section{BAHAN DAN METODE}

Penelitian ini dilaksanakan di Kebun Percobaan Balai Pengkajian Teknologi Pertanian (BPTP) Unit Percobaan Natar, Desa Negara Ratu, Kecamatan Natar, Kabupaten Lampung Selatan dan Laboratorium Ilmu Tanaman Fakultas Pertanian, Universitas Lampung dari bulan Juli sampai Desember 2014. Lokasi penelitian berada pada ketinggian 135 mdpl dan mempunyai jenis tanah latosol dan sebagian podsolik merah kuning (PMK), serta iklim nya termasuk tipe B, menurut Schmidt dan Ferguson (1951) dengan curah hujan ratarata $1.786 \mathrm{~mm} /$ tahun (Departemen Pertanian, 2009).

Bahan dan alat yang digunakan yaitu stek ubikayu varietas UJ-5 yang sudah berumur 10-12 bulan, paclobutrazol, meteran, jangka sorong dan chlorophyll meter. Percobaan disusun dalam Rancangan Acak Kelompok (RAK) dengan tiga ulangan. Perlakuan yang diterapkan yaitu konsentrasi dan frekuensi aplikasi paclobutrazol. Perlakuan terdiri atas $0 \mathrm{ppm}(\mathrm{P} 0), 200 \mathrm{ppm}$ dengan 2 kali aplikasi (P1), 200 ppm dengan 3 kali aplikasi (P2), 400 ppm dengan 2 kali aplikasi (P3), 400 ppm dengan 3 kali aplikasi (P4), 600 ppm dengan 2 kali aplikasi (P5), dan 600 ppm dengan 3 kali aplikasi (P6). Setiap satu satuan percobaan terdiri atas 3 tanaman contoh.

Penanaman stek ubikayu dilakukan di polibag berukuran $10 \mathrm{~kg}$ sebanyak 63 polibag. Setiap polibag diisi media pupuk kandang dan tanah dengan perbandingan $1: 4$. Pemupukan dilakukan secara bertahap sebanyak 2 kali yaitu pemupukan tahap I pada saat 1 minggu setelah tanam dengan dosis Urea 5 gram per tanaman, SP-36 10 gram per tanaman dan $\mathrm{KCl} 10$ gram per tanaman setara dengan $100 \mathrm{~kg} \mathrm{ha}^{-1}$ Urea, $100 \mathrm{~kg} \mathrm{ha}^{-1}$ SP-36, dan $200 \mathrm{~kg} \mathrm{ha}^{-1} \mathrm{KCl}$. Pemupukan tahap II dilakukan pada saat umur tanaman ubikayu mencapai 2 bulan setelah tanam dengan sisa dosis pemupukan tahap I. Aplikasi paclobutrazol dilakukan sesuai perlakuan yaitu sebanyak 2 dan 3 kali dengan interval waktu aplikasi dua minggu, sehingga aplikasi paclobutrazol dilakukan pada $30 \mathrm{HST}$, $44 \mathrm{HST}$, dan 58 HST. Aplikasi dilakukan dengan cara penyemprotan kebagian tanaman (spray).

Variabel pengamatan dalam penelitian yaitu tinggi tanaman, jumlah daun, diameter batang, tingkat kehijauan daun, bobot kering daun dan bobot basah ubi. Pengamatan dilakukan mulai dari 4 MST.

\section{HASIL DAN PEMBAHASAN}

Aplikasi paclobutrazol dengan konsentrasi dan frekuensi berbeda berpengaruh nyata terhadap tinggi tanaman ubikayu. Tabel 1 dan Tabel 2 menunjukkan bahwa pemberian paclobutrazol dapat menekan tinggi tanaman ubi kayu yang mulai terlihat pada umur 7 sampai

Tabel 1. Pengaruh aplikasi paclobutrazol dengan konsentrasi dan frekuensi berbeda terhadap tinggi tanaman ubikayu (cm).

\begin{tabular}{lccccc}
\hline \multirow{2}{*}{ Perlakuan } & \multicolumn{7}{c}{ Umur Tanaman (mst) } \\
\cline { 2 - 6 } & 7 & 8 & 9 & 10 \\
\hline $0 \quad$ ppm & $21,53 \mathrm{a}$ & $23,17 \mathrm{a}$ & $25,06 \mathrm{a}$ & $27,11 \mathrm{a}$ \\
200 ppm (2x aplikasi) & $17,61 \mathrm{bc}$ & $18,06 \mathrm{bc}$ & $19,86 \mathrm{bc}$ & $20,21 \mathrm{bc}$ \\
200 ppm (3x aplikasi) & $16,03 \mathrm{c}$ & $16,34 \mathrm{c}$ & $16,92 \mathrm{c}$ & $17,38 \mathrm{c}$ \\
400 ppm (2x aplikasi) & $17,11 \mathrm{bc}$ & $17,01 \mathrm{bc}$ & $17,44 \mathrm{bc}$ & $17,72 \mathrm{bc}$ \\
400 ppm (3x aplikasi) & $19,10 \mathrm{abc}$ & $19,43 \mathrm{bc}$ & $19,93 \mathrm{bc}$ & $20,50 \mathrm{bc}$ \\
600 ppm (2x aplikasi) & $19,52 \mathrm{ab}$ & $20,14 \mathrm{ab}$ & $20,47 \mathrm{~b}$ & $20,69 \mathrm{~b}$ \\
600 ppm (3x aplikasi) & $16,50 \mathrm{bc}$ & $16,90 \mathrm{bc}$ & $17,38 \mathrm{bc}$ & $17,87 \mathrm{bc}$ \\
\hline BNT 5\% & 3,13 & 3,31 & 3,31 & 3,16 \\
\hline
\end{tabular}

Keterangan : Dua nilai tengah yang diikuti huruf yang sama dinyatakan tidak berbeda menurut uji BNT pada taraf $5 \%$ 
Tabel 2. Pengaruh aplikasi paclobutrazol dengan konsentrasi dan frekuensi berbeda terhadap tinggi tanaman ubikayu (cm).

\begin{tabular}{|c|c|c|c|c|c|c|}
\hline \multirow{2}{*}{ Perlakuan } & \multicolumn{6}{|c|}{ Umur Tanaman (mst) } \\
\hline & 12 & 14 & & 16 & & 18 \\
\hline $0 \quad \mathrm{ppm}$ & $33,97 \quad a$ & 47,39 & $\mathrm{a}$ & 58,36 & $\mathrm{a}$ & 77,37 a \\
\hline 200 ppm (2x aplikasi) & $25,24 \quad b$ & 37,97 & $\mathrm{~b}$ & 50,18 & $\mathrm{a}$ & $69,82 \quad a b$ \\
\hline 200 ppm (3x aplikasi) & $19,51 \mathrm{c}$ & 21,89 & $\mathrm{c}$ & 28,52 & $\mathrm{c}$ & $49,83 \mathrm{bc}$ \\
\hline 400 ppm (2x aplikasi) & $18,69 \mathrm{c}$ & 23,78 & $\mathrm{c}$ & 33,29 & $\mathrm{bc}$ & $53,66 \mathrm{bc}$ \\
\hline 400 ppm (3x aplikasi) & 22,84 bc & 24,71 & $\mathrm{c}$ & 30,22 & $\mathrm{bc}$ & $47,72 \mathrm{c}$ \\
\hline 600 ppm (2x aplikasi) & $22,60 \mathrm{bc}$ & 30,59 & $\mathrm{bc}$ & 44,06 & $a b$ & 61,94 abc \\
\hline 600 ppm (3x aplikasi) & $19,62 \mathrm{c}$ & 23,49 & $\mathrm{c}$ & 27,08 & $\mathrm{c}$ & $40,41 \quad \mathrm{c}$ \\
\hline BNT 5\% & 5,31 & 9,23 & & 14,31 & & 21,58 \\
\hline
\end{tabular}

Keterangan : Dua nilai tengah yang diikuti huruf yang sama dinyatakan tidak berbeda menurut uji BNT pada taraf $5 \%$

Tabel 3. Pengaruh aplikasi paclobutrazol dengan konsentrasi dan frekuensi berbeda terhadap diameter batang tanaman ubikayu $(\mathrm{cm})$.

\begin{tabular}{lllll}
\hline \multirow{2}{*}{ Perlakuan } & \multicolumn{5}{c}{ Umur tanaman (mst) } \\
\cline { 2 - 5 } & 9 & 10 & 11 & 12 \\
\hline $0 \quad$ ppm & $0,93 \mathrm{a}$ & $0,94 \mathrm{a}$ & $0,95 \mathrm{a}$ & $0,99 \mathrm{a}$ \\
$200 \mathrm{ppm}$ (2x aplikasi) & $0,83 \mathrm{ab}$ & $0,85 \mathrm{ab}$ & $0,86 \mathrm{ab}$ & $0,90 \mathrm{ab}$ \\
200 ppm (3x aplikasi) & $0,75 \mathrm{bc}$ & $0,76 \mathrm{c}$ & $0,78 \mathrm{bc}$ & $0,81 \mathrm{c}$ \\
$400 \mathrm{ppm}$ (2x aplikasi) & $0,77 \mathrm{bc}$ & $0,79 \mathrm{bc}$ & $0,8 \mathrm{bc}$ & $0,83 \mathrm{bc}$ \\
$400 \mathrm{ppm}$ (3x aplikasi) & $0,76 \mathrm{bc}$ & $0,8 \mathrm{bc}$ & $0,81 \mathrm{bc}$ & $0,83 \mathrm{bc}$ \\
$600 \mathrm{ppm}$ (2x aplikasi) & $0,75 \mathrm{bc}$ & $0,78 \mathrm{bc}$ & $0,8 \mathrm{bc}$ & $0,84 \mathrm{bc}$ \\
600 ppm (3x aplikasi) & $0,7 \mathrm{c}$ & $0,72 \mathrm{c}$ & $0,75 \mathrm{c}$ & $0,78 \mathrm{c}$ \\
\hline BNT 5\% & 0,1 & 0,09 & 0,1 & 0,1 \\
\hline
\end{tabular}

Keterangan : Dua nilai tengah yang diikuti huruf yang sama dinyatakan tidak berbeda menurut uji BNT pada taraf $5 \%$

19 mst. Pertumbuhan tinggi diamati sejak tanaman ubikayu berumur 4 mst hingga 19 mst.

Hal ini didukung hasil penelitian Teddy (2012) yang menyatakan bahwa semua tanaman ubikayu yang diberi perlakuan paclobutrazol memiliki tinggi yang lebih rendah dibandingkan dengan tanaman ubikayu yang tidak diberi perlakuan paclobutrazol. Hal ini disebabkan karena terjadi penghambatan panjang ruas pada tunas tanaman yaitu kira-kira sebesar $4,2 \mathrm{~cm}$. Namun pemberian paclobutrazol 200 ppm dengan 2 kali aplikasi hanya mampu menekan tinggi tunas sampai 15 mst dan selanjutnya mengalami peningkatan tinggi yang cukup signifikan. Perbedaan penekanan tinggi tanaman tidak terlalu tampak antarperlakuan paclobutrazol 400 dan $600 \mathrm{ppm}$.

Tabel 1 dan Tabel 2 menunjukkan bahwa pengaruh aplikasi paclobutrazol terhadap tinggi tanaman memberikan perbedaan yang tidak terlalu signifikan antarperlakuan konsentrasi 200, 400 dan 600 ppm. Data tersebut tampaknya mengarah pada dugaan kemampuan paclobutrazol yang menekan pertumbuhan tinggi tanaman hampir sama berapapun konsentrasinya. Paclobutrazol memiliki sifat sistemik artinya perlakuan yang konsentrasinya rendah diimbangi dengan frekuensi pemberian yang lebih banyak, maka bahan aktif yang diterima tanaman terakumulasi sama banyaknya dengan 
Tabel 4. Pengaruh aplikasi paclobutrazol dengan konsentrasi dan frekuensi berbeda terhadap tingkat kehijauan daun tanaman ubikayu (unit).

\begin{tabular}{lcccc}
\hline \multirow{2}{*}{ Perlakuan } & \multicolumn{4}{c}{ Umur tanaman (mst) } \\
\cline { 2 - 5 } & 9 & 12 & 13 & 14 \\
\hline $0 \quad$ ppm & $35,88 \mathrm{~d}$ & $35,93 \mathrm{c}$ & $38,16 \mathrm{c}$ & $37,33 \mathrm{~b}$ \\
200 ppm (2x aplikasi) & $40,76 \mathrm{bc}$ & $41,63 \mathrm{ab}$ & $38,78 \mathrm{bc}$ & $38,07 \mathrm{~b}$ \\
200 ppm (3x aplikasi) & $38,23 \mathrm{~cd}$ & $39,98 \mathrm{bc}$ & $40,73 \mathrm{abc}$ & $39,49 \mathrm{ab}$ \\
400 ppm (2x aplikasi) & $40,67 \mathrm{bc}$ & $41,06 \mathrm{ab}$ & $42,06 \mathrm{ab}$ & $42,79 \mathrm{a}$ \\
400 ppm (3x aplikasi) & $39,76 \mathrm{bcd}$ & $42,29 \mathrm{ab}$ & $42,89 \mathrm{a}$ & $39,99 \mathrm{ab}$ \\
600 ppm (2x aplikasi) & $42,39 \mathrm{ab}$ & $41,91 \mathrm{ab}$ & $42,38 \mathrm{ab}$ & $42,96 \mathrm{a}$ \\
600 ppm (3x aplikasi) & $45,46 \mathrm{a}$ & $44,54 \mathrm{a}$ & $44,06 \mathrm{a}$ & $42,72 \mathrm{a}$ \\
\hline BNT 5\% & 3,91 & 4,05 & 3,71 & 3,71 \\
\hline
\end{tabular}

Keterangan : Dua nilai tengah yang diikuti huruf yang sama dinyatakan tidak berbeda menurut uji BNT pada taraf $5 \%$

Tabel 5. Pengaruh aplikasi paclobutrazol dengan konsentrasi dan frekuensi berbeda terhadap tingkat kehijauan daun tanaman ubikayu (unit).

\begin{tabular}{lccc}
\hline \multirow{2}{*}{ Perlakuan } & \multicolumn{3}{c}{ Umur tanaman (mst) } \\
\cline { 2 - 4 } & 15 & 16 & 17 \\
\hline $0 \quad$ ppm & $35,48 \mathrm{c}$ & $37,69 \mathrm{c}$ & $37,44 \mathrm{~d}$ \\
$200 \mathrm{ppm}$ (2x aplikasi) & $40,31 \mathrm{~b}$ & $39,73 \mathrm{bc}$ & $40,89 \mathrm{bcd}$ \\
$200 \mathrm{ppm}$ (3x aplikasi) & $41,04 \mathrm{ab}$ & $40,20 \mathrm{bc}$ & $39,58 \mathrm{~cd}$ \\
$400 \mathrm{ppm}$ (2x aplikasi) & $40,82 \mathrm{ab}$ & $39,29 \mathrm{bc}$ & $39,48 \mathrm{~cd}$ \\
$400 \mathrm{ppm}$ (3x aplikasi) & $41,59 \mathrm{ab}$ & $42,21 \mathrm{ab}$ & $44,18 \mathrm{ab}$ \\
$600 \mathrm{ppm}(2 \mathrm{x}$ aplikasi) & $42,42 \mathrm{ab}$ & $46,33 \mathrm{a}$ & $41,66 \mathrm{abc}$ \\
600 ppm (3x aplikasi) & $44,51 \mathrm{a}$ & $41,39 \mathrm{bc}$ & $45,13 \mathrm{a}$ \\
\hline BNT 5\% & 4,11 & 4,19 & 4,18 \\
\hline
\end{tabular}

Keterangan : Dua nilai tengah yang diikuti huruf yang sama dinyatakan tidak berbeda menurut uji BNT pada taraf $5 \%$

perlakuan yang konsentrasinya tinggi dan frekuensi pemberian yang lebih sedikit (Syam'un, 2008). Tanaman yang tidak diberi perlakuan paclobutrazol mengalami peningkatan tinggi tanaman yang cukup signifikan, sedangkan tanaman yang diberi perlakuan paclobutrazol mengalami stagnasi beberapa minggu yaitu mulai dari 5 mst sampai 11 mst. Namun pemberian paclobutrazol 200 ppm dengan 2 kali aplikasi mampu mengalami peningkatan tinggi yang cukup signifikan setelah mengalami stagnasi beberapa minggu (Gambar 1a).

Penghambatan tinggi tanaman berkaitan dengan terhambatnya produksi giberelin akibat pemberian paclobutrazol. Paclobutrazol menghambat sintesis giberelin dengan cara menghambat oksidasi kaurene menjadi asam kaurenat. Pertumbuhan memanjang sel diatur/ distimulasi oleh zat pengatur tumbuh (growth regulator) asam giberelin (Chaney, 2004). Aplikasi paclobutrazol dengan konsentrasi dan frekuensi berbeda berpengaruh nyata terhadap diameter batang tanaman ubikayu. Aplikasi paclobutrazol menekan diameter batang tanaman ubikayu umur 9 sampai 12 mst.

Tabel 3 menunjukkan bahwa tanaman ubikayu yang diberi perlakuan paclobutrazol memiliki diameter batang yang lebih kecil dibandingkan dengan yang tidak 
Tabel 6. Pengaruh aplikasi paclobutrazol dengan konsentrasi dan frekuensi berbeda terhadap bobot basah ubi dan bobot kering daun tanaman ubikayu.

\begin{tabular}{lcc}
\hline Perlakuan & $\begin{array}{c}\text { Bobot basah ubi } \\
(\mathrm{g} / \text { tanaman })\end{array}$ & $\begin{array}{c}\text { Bobot kering daun } \\
(\mathrm{g} / \text { tanaman })\end{array}$ \\
\hline $0 \quad \mathrm{ppm}$ & $1.345,33 \mathrm{a}$ & $114,58 \mathrm{a}$ \\
$200 \mathrm{ppm}$ (2x aplikasi) & $1.004,00 \mathrm{ab}$ & $99,02 \mathrm{ab}$ \\
$200 \mathrm{ppm}(3 \mathrm{x}$ aplikasi) & $509,11 \mathrm{c}$ & $60,37 \mathrm{c}$ \\
$400 \mathrm{ppm}(2 \mathrm{x}$ aplikasi) & $425,89 \mathrm{c}$ & $61,97 \mathrm{c}$ \\
$400 \mathrm{ppm}(3 \mathrm{x}$ aplikasi) & $687,33 \mathrm{bc}$ & $71,78 \mathrm{bc}$ \\
$600 \mathrm{ppm}(2 \mathrm{x}$ aplikasi) & $803,89 \mathrm{bc}$ & $69,48 \mathrm{bc}$ \\
$600 \mathrm{ppm}(3 \mathrm{x}$ aplikasi) & $502,11 \mathrm{c}$ & $67,91 \mathrm{c}$ \\
\hline BNT 5\% & 457,18 & 30,67 \\
\hline
\end{tabular}

Keterangan : Dua nilai tengah yang diikuti huruf yang sama dinyatakan tidak berbeda menurut uji BNT pada taraf $5 \%$


Gambar 1. Keragaan tinggi tanaman (a) dan diameter batang (b) tanaman ubikayu akibat aplikasi paclobutrazol dengan konsentrasi dan frekuensi berbeda pada umur tanam berbeda. $\bullet-\mathbf{- P} 0,-\square=\mathrm{P} 1, \boldsymbol{-}=\mathrm{P} 2$, $\boldsymbol{-}-\mathrm{P} 3,-\square-=\mathrm{P} 4,-\triangle-=\mathrm{P} 5,-\mathrm{O}-=\mathrm{P} 6$.

diberi perlakuan paclobutrazol. Hal ini disebabkan karena terjadi penghambatan ukuran diameter batang tanaman yaitu kira-kira sebesar $0,1 \mathrm{~cm}$. Pemberian paclobutrazol $200 \mathrm{ppm}$ dengan 2 kali aplikasi tidak mampu menekan diameter batang tanaman ubi kayu mulai dari 9 mst sampai 19 mst (Gambar 1b). Menurut Krishnamoorthy (1981), Paclobutrazol menghambat sintesis giberelin dengan cara menghambat oksidasi kaurene menjadi asam kaurenat. Terhambatnya sintesis giberelin mengakibatkan pemanjangan sel pada meristem sub-apikal berjalan lambat. Aplikasi paclobutrazol dengan konsentrasi dan frekuensi berbeda berpengaruh nyata terhadap tingkat kehijauan daun tanaman ubi kayu. Tabel 4 dan Tabel 5 menunjukkan bahwa tanaman ubikayu yang diberi perlakuan paclobutrazol memiliki tingkat kehijauan daun yang berbeda dengan yang tidak diberi perlakuan paclobutrazol. Dalziel dan Lawrence dalam Davis, dkk., (1988) melaporkan bahwa kandungan klorofil pada kloroplast meningkat pada tanaman Beta vulgaris yang diberi paclobutrazol.

Aplikasi paclobutrazol dengan konsentrasi dan frekuensi berbeda berpengaruh nyata terhadap bobot basah ubi dan bobot kering daun tanaman ubi kayu. Tabel 6 menunjukkan bahwa tanaman ubi kayu yang diberi 
perlakuan paclobutrazol memiliki bobot kering daun yang lebih rendah dibandingkan dengan yang tidak diberi perlakuan paclobutrazol. Hal ini terjadi karena terhambatnya atau terganggunya proses fotosintesis yang menyebabkan produksi glukosa sedikit dan asimilat tidak dapat didistribusikan secara maksimal menuju ubi, batang dan daun sehingga bobot kering maupun basah komponen daun dan ubi lebih rendah dibandingkan perlakuan yang tidak diberi perlakuan paclobutrazol.

Hasil penelitian Ani (2004) menyatakan bahwa perlakuan paclobutrazol pada konsentrasi $50 \mathrm{ppm}$ dan 100 ppm dapat menurunkan jumlah dan bobot ubi kentang per plot dibandingkan dengan kontrol. Namun demikian, pemberian paclobutrazol 200 ppm dengan 2 kali aplikasi tidak mampu menekan bobot basah ubi tanaman ubi kayu secara nyata. Hasil penelitian Catur (2014) menunjukkan bahwa pemberian paclobutrazol dengan konsentrasi 500 ppm mampu menekan bobot basah dan kering ubi tanaman ubi kayu. Namun demikian, pemberian paclobutrazol 200 ppm dengan 2 kali aplikasi tidak menekan bobot kering daun tanaman ubi kayu.

Aplikasi paclobutrazol dapat menghambat pertumbuhan tanaman ubi kayu dengan menekan tinggi tanaman, diameter batang, bobot basah ubi dan bobot kering daun. Namun terdapat cara aplikasi paclobutrazol yang bisa menghambat pertumbuhan tanaman ubikayu yang bersifat sementara yaitu aplikasi paclobutrazol dengan konsentrasi 200 ppm dan 2 kali aplikasi, dengan menghambat tinggi tanaman ubi kayu selama 7 minggu. Sehingga dapat dilakukan sistem tumpangsari dengan tanaman palawija pada pertanaman ubi kayu tanpa terjadi persaingan, terutama persaingan cahaya matahari akibat tajuk tanaman ubi kayu. Dengan demikian tanaman palawija dapat tumbuh dengan optimal dan pada akhirnya setelah tanaman palawija dipanen, tanaman ubi kayu akan tumbuh normal sampai saat panen tanpa mengurangi hasil ubi kayu.

\section{KESIMPULAN}

Berdasarkan hasil penelitian dan pembahasan maka dapat diambil kesimpulan bahwa aplikasi paclobutrazol dengan konsentrasi dan frekuensi berbeda berpengaruh terhadap pertumbuhan tajuk tanaman ubikayu.

Penelitian ini juga menyimpulkan bahwa pemberian paclobutrazol konsentrasi 200 ppm dengan 2 kali aplikasi menghambat sementara tajuk tanaman ubi kayu dengan menghambat tinggi tanaman kira-kira sebesar 4,2 cm selama 7 minggu, tetapi tidak menurunkan bobot umbi secara nyata.

\section{DAFTAR PUSTAKA}

Ani, N. 2004. Pengaruh konsentrasi paclobutrazol dan urea pada stek kentang terhadap produksi tuberlet varietas Granola. Jurnal Penelitian Bidang Ilmu Pertanian. Vol. 2 (1): 29-35.

Berova, M., Z. Zlatev, dan N. Stoeva. 2002. Effect of paclobutrazol on wheat seedling under low temperature stress. Jurnal Plant Physical. Bulgaria. 35 (3):76-81.

Catur, R. 2014. Pengaruh pemberian paclobutrazol melalui daun berbagai volume terhadap pembungaan tanaman ubikayu. Skripsi. Lampung: Universitas Lampung

Chaney, W. R. 2004. Paclobutrazol: More than just a growth retardant. Presented at Pro-Hort Conference, Peoria, Illinois.

Davis, T. D., G. L. Steffens, dan Sankla. 1988. Triazol Plant Growth Regulator. In J. Janick (Ed). Hort. Rev $10: 105$. Timber Press. Portland. Oregon.

Departemen Pertanian. 2009. Sekilas Kebun Percobaan Natar. Balai Pengkajian Teknologi Pertanian. Lampung.

Hafsah, M.J. 2003. Bisnis Ubi kayu Indonesia. Pustaka Sinar Harapan. Jakarta. 263p.

Kamal, M. 2011. Kajian Sinergi Pemanfaatan Cahaya dan Nitrogen dalam Produksi Tanaman Pangan. Pidato ilmiah dalam rangka pengukuhan guru besar dalam bidang ilmu tanaman Fakultas Pertanian Universitas Lampung di Bandarlampung pada tanggal 23 Februari 2011. Penerbit Universitas Lampung. Bandar Lampung. $68 \mathrm{hlm}$.

Khrisnamoorthy, H. N.1981. Plant Growth Substances Including Aplication in Agriculture. Tata Mc. Graw-Hill Pub. Co. Ltd. New Delhi. 241 p.

Schmidt, F.H. dan J. H. A. Ferguson. 1951. Rainfall type based on wet and dry period ratio for Indonesia with Western New Guinea. Kementrian Perhubungan. Jawatan Meteorologi dan Geofisika. Jakarta.

Syahid, S. F. 2007. Pengaruh retardan paclobutrazol terhadap pertumbuhan temulawak (Curcuma xanthorrhiza) selama konservasi in vitro. Jurnal Littri. 13 (3): 93-97. 
Syam'un, E., F. Haring, dan Rahmawati. 2008. Pertumbuhan dan pembungaan krisan pada berbagai konsentrasi dan frekuensi pemberian paclobutrazol. J. Arivigor. 7(2):170-179.

Teddy, C. 2012. Pengaruh aplikasi paclobutrazol dan $\mathrm{KNO}_{3}$ terhadap kemampuan dan pertumbuhan tajuk tanaman ubi kayu (Manihot esculenta). Skripsi. Lampung: Universitas Lampung.

Watson GW. 2006. The effect of paclobutrazol treatment on starch content, mychorrizal colonization, and fine root density of white oaks (Quercus alba L.). Journal of Arboriculture 32 (3): 114-117. 